\title{
Anionic Wormlike Micellar Fluids that Display Cloud Points: Rheology and Phase Behavior
}

\author{
Gokul C. Kalur ${ }^{\dagger}$ and Srinivasa R. Raghavan* \\ Department of Chemical Engineering, University of Maryland, College Park, Maryland 20742-2111
}

Received: December 28, 2004; In Final Form: March 4, 2005

\begin{abstract}
We report our investigations into the self-assembly of sodium oleate (NaOA) in the presence of a binding salt (triethylammonium chloride, $\mathrm{Et}_{3} \mathrm{NHCl}$ ) simple salt (potassium chloride, $\mathrm{KCl}$ ). Both salts promote the growth of long, wormlike micelles in $\mathrm{NaOA}$ solutions, thereby increasing the fluid viscosity. The significant difference with the $\mathrm{Et}_{3} \mathrm{NHCl}$ salt is that it also modifies the phase behavior of $\mathrm{NaOA}$ solutions. Specifically, $\mathrm{NaOA} / \mathrm{Et}_{3} \mathrm{NHCl}$ solutions display cloud points upon heating, followed by phase separation into two liquid phases. Such cloud point behavior is rarely observed in ionic surfactant systems, although it is common in nonionic surfactant solutions. Interestingly, while cloud points are not observed with $\mathrm{KCl}$, the addition of $\mathrm{KCl}$ to $\mathrm{NaOA} / \mathrm{Et}_{3} \mathrm{NHCl}$ solutions further lowers the cloud point temperature. Also, in the case of tetraethylammonium halide salt, neither a cloud point nor an increase in viscosity is observed. The clouding in the case of $\mathrm{Et}_{3} \mathrm{NHCl}$ is attributed to the temperature-induced aggregation of anionic micelles whose surface is covered by bound counterions.
\end{abstract}

\section{Introduction}

It is well-known that cationic surfactants can self-assemble in aqueous solution into long, flexible cylindrical micelles (wormlike micelles) upon the addition of salts. ${ }^{1-4}$ These wormlike micelles, with lengths on the order of a few microns and radii of $\sim 2 \mathrm{~nm}$, become entangled into a transient network, thereby enhancing the viscoelasticity of the fluid. The salt serves to reduce the electrostatic interactions between the cationic headgroups, thus reducing the effective area per headgroup and thereby promoting the growth of cylindrical aggregates at the expense of spherical ones. Two types of salts are typically distinguished: simple salts, such as sodium chloride $(\mathrm{NaCl})$ or potassium chloride $(\mathrm{KCl})$, which simply shrink the ionic double layer around each headgroup, and binding salts, which also reduce the surface charge by binding their counterions to the cationic micelle. ${ }^{2}$ Thus, binding salts, with counterions such as salicylate, tosylate, or chlorobenzoate, tend to induce micellar growth at very low concentrations.

Much less is known, in comparison, regarding the ability of anionic surfactants to form wormlike micelles or regarding the rheological properties of these micelles. Among the few studies that exist, the majority have focused on sodium dodecyl sulfate (SDS) as their surfactant of choice. ${ }^{5,6}$ Examples of binding salts for anionic wormlike micelles are also relatively scarce. Recently, one of us was involved in a study where we identified $p$-toluidine hydrochloride (PTHC) as a binding salt that could rapidly induce the growth of SDS worms. ${ }^{6}$ One issue with using SDS to form wormlike micelles is that the zero-shear viscosity of these solutions is typically quite low $(\sim 1 \mathrm{~Pa} \cdot \mathrm{s})$. This is probably related to the short $\left(\mathrm{C}_{12}\right)$ tail length of SDS, whereas, in comparison, popular worm-forming cationic surfactants (e.g., cetyl trimethylammonium bromide, CTAB) have 16 carbons or more in their tails. ${ }^{2}$ As we will show in this study, it is possible to achieve much higher viscosities by using an 18-carbon-tailed anionic soap, sodium oleate.

\footnotetext{
* Corresponding author. E-mail: sraghava@eng.umd.edu.

$\dagger$ Present address: Irix Pharmaceuticals, Inc., Florence, SC.
}

Anionic wormlike micelles could offer advantages over their cationic counterparts in many applications, including enhanced oil recovery. ${ }^{7}$ For example, anionic systems tend to be biodegradable and less toxic compared to cationic ones and are therefore considered to be more environmentally friendly. In many applications, the stability of these micellar solutions at elevated temperatures is of importance..$^{4,7}$ Therefore, the phase behavior of these solutions as a function of temperature must also be studied.

In the context of temperature-dependent phase behavior, it is well-known that aqueous solutions of nonionic surfactants tend to phase separate upon heating. ${ }^{8}$ These solutions turn cloudy at a particular temperature, called the "cloud point", and at higher temperatures they demix into two liquid phases of welldefined composition. Cloud point phenomena, or, more properly, lower consolute phase behavior, are rarely observed for ionic surfactant solutions, however. The few instances of cloud points in cationic surfactant solutions have been enumerated recently by Raghavan et al. ${ }^{9}$ In the case of anionic surfactants, the first instance of cloud point behavior was reported by $\mathrm{Yu}$ and $\mathrm{Xu}^{10}$ for the surfactant sodium tetradecyl sulfate upon addition of an equimolar amount of the quarternary ammonium salt tetrabutylammonium bromide. Subsequently, a range of similar quarternary ammonium salts $\left(\mathrm{R}_{4} \mathrm{~N}^{+}\right)$was investigated by others in conjunction with anionic surfactants such as SDS. ${ }^{11-16}$ Cloud points were found when the alkyl moiety $(\mathrm{R})$ was quite large (e.g., butyl and above). The viscosities of these micellar solutions were reported to be at most 5 times that of water, suggesting that the micelles are quite small (ellipsoids, short rods, or spheres). No evidence for the presence of wormlike micelles, such as viscoelastic effects, was presented.

In this paper, we describe wormlike micelles formed by the $\mathrm{C}_{18}$-tailed anionic surfactant sodium oleate (NaOA) upon addition of various salts. We show that the addition of triethylammonium chloride $\left(\mathrm{Et}_{3} \mathrm{NHCl}\right)$ to $\mathrm{NaOA}$ solutions transforms both their phase behavior and the rheology. In terms of phase behavior, the solutions now exhibit cloud points, while rheologically, they show a viscoelastic response indicative of 
wormlike micelles. In contrast, the addition of a simple salt, $\mathrm{KCl}$, gives rise to highly viscoelastic fluids, but no cloud point behavior is seen. Indeed, we observe cloud points only with certain counterions, and we attempt to rationalize these observations through qualitative arguments. Cloud point phenomena are not only of academic interest, but could also form the basis for certain types of extractive separations. ${ }^{17}$

\section{Experimental Section}

Materials. Sodium oleate $(\mathrm{NaOA})$ of purity $>95 \%$ was obtained from TCI. Potassium chloride $(\mathrm{KCl})$, triethylammonium chloride $\left(\mathrm{Et}_{3} \mathrm{NHCl}\right)$, tetraethylammonium bromide $\left(\mathrm{Et}_{4} \mathrm{NBr}\right)$, and tetrabutylammonium bromide $\left(\mathrm{Bu}_{4} \mathrm{NBr}\right)$ were obtained from Aldrich (all were $>98 \%$ in purity). The reagents were used without further purification. Samples were prepared using distilled-deionized water. Solutions of $\mathrm{NaOA}$ were prepared at $\mathrm{pH} 10$ to prevent soap hydrolysis and subsequent formation of acid soap crystals. ${ }^{18} \mathrm{NaOA} /$ salt samples were made by adding the salt to NaOA solutions, followed by mild heat while stirring. Samples were stored for at least 1 day prior to further testing.

Phase Behavior. Phase behavior was recorded by visual observation. The phase boundaries as a function of temperature were determined by noting the incipient clouding of a sample on heating. The transition temperatures (cloud points) reported here are reproducible to within $\pm 0.5^{\circ} \mathrm{C}$.

Rheology. Steady and dynamic rheological experiments were performed on Rheometrics strain-controlled (RDAIII) and stresscontrolled (SR5) rheometers. Cone and plate geometries were used in each case. The temperature was controlled using Peltier plates to $\pm 0.1^{\circ} \mathrm{C}$ of the desired value. A solvent trap was used to minimize water evaporation. Frequency spectra were conducted in the linear viscoelastic regime of the samples, as determined from dynamic strain sweep measurements.

Small-Angle Neutron Scattering (SANS). SANS measurements were made on the NG-3 $(30 \mathrm{~m})$ beamline at NIST in Gaithersburg, MD. Samples were studied in $2 \mathrm{~mm}$ quartz cells. The scattering spectra were corrected and placed on an absolute scale using calibration standards provided by NIST. The data are shown for the radially averaged intensity $I$ versus the scattering vector $q=(4 \pi / \lambda) \sin (\theta / 2)$, where $\lambda$ is the wavelength of incident neutrons and $\theta$ is the scattering angle.

\section{Results}

NaOA/KCl Solutions. We first describe the effects of adding $\mathrm{KCl}$ to $\mathrm{NaOA}$ solutions, with the $\mathrm{NaOA}$ molar concentration fixed at $50 \mathrm{mM}$. The addition of $\mathrm{KCl}$ gives rise to highly viscoelastic solutions. Figure 1 shows the rheology at $25^{\circ} \mathrm{C}$ of a sample containing $50 \mathrm{mM} \mathrm{NaOA}$ and $600 \mathrm{mM} \mathrm{KCl}$. The dynamic rheology data (Figure 1a) shows the elastic modulus $G^{\prime}$ and the viscous modulus $G^{\prime \prime}$ as functions of frequency $\omega$. At high $\omega$, the sample behavior is elastic ( $G^{\prime}$ shows a plateau and dominates over $\left.G^{\prime \prime}\right)$, whereas at low $\omega$ or long time scales the sample shows a viscous behavior $\left(G^{\prime \prime}\right.$ exceeds $G^{\prime}$ and the slopes of $G^{\prime}$ and $G^{\prime \prime}$ are 2 and 1 , respectively). Taken together, the sample shows a viscoelastic response and its relaxation time $t_{\mathrm{R}}$ can be estimated as $1 / \omega_{\mathrm{c}}$, where $\omega_{\mathrm{c}}$ is the characteristic frequency at which $G^{\prime}$ and $G^{\prime \prime}$ cross.

In Figure 1a, the lines through the data are fits to a Maxwell model with a single relaxation time. The moduli predicted by this model are given by ${ }^{2}$

$$
G^{\prime}(\omega)=\frac{G_{0} t_{\mathrm{R}}{ }^{2} \omega^{2}}{1+t_{\mathrm{R}}{ }^{2} \omega^{2}} ; \quad G^{\prime \prime}(\omega)=\frac{G_{0} t_{\mathrm{R}} \omega}{1+t_{\mathrm{R}}{ }^{2} \omega^{2}}
$$
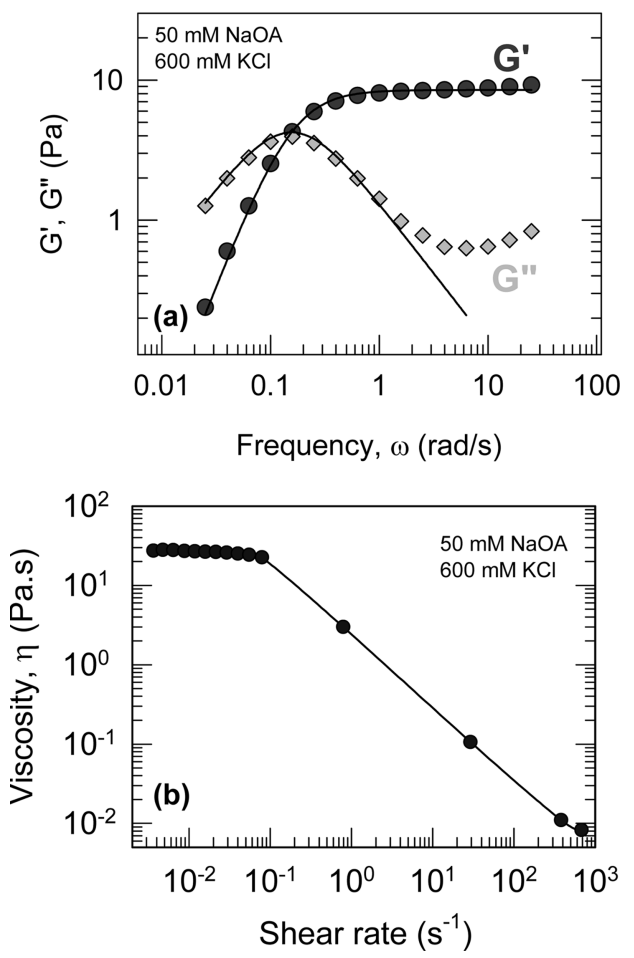

Figure 1. Typical rheology at $25^{\circ} \mathrm{C}$ of an $\mathrm{NaOA} / \mathrm{KCl}$ solution under (a) dynamic shear and (b) steady shear. The sample contains $50 \mathrm{mM}$ $\mathrm{NaOA}$ and $600 \mathrm{mM} \mathrm{KCl}$. The lines in (a) are fits to a Maxwell model.

Here, $G_{0}$ is the plateau modulus, i.e., the value of $G^{\prime}$ at high frequencies. The Maxwell model fits the data well at low and intermediate frequencies, confirming that a single relaxation time dominates the response. Such viscoelastic behavior in accordance with the Maxwell model is indicative of entangled wormlike micelles. The departure of $G^{\prime \prime}$ from the Maxwell model prediction at high $\omega$ is another striking feature in the rheology of wormlike micelles. ${ }^{1}$ This is attributed to the fact that wormlike micelles are dynamic entities that are rapidly breaking and recombining. ${ }^{1,2}$

Figure 1b shows the corresponding steady-shear rheology of the same $\mathrm{NaOA} / \mathrm{KCl}$ sample. The viscosity shows a Newtonian plateau at low shear rates and drops at higher shear rates. The value of the zero-shear viscosity $\eta_{0}$ is about $30 \mathrm{~Pa} \cdot \mathrm{s}$ for this sample. This value is consistent with that obtained from the dynamic data in Figure 1a using the relation $\eta_{0}=G_{0} t_{\mathrm{R}}$, which is exact for a Maxwell fluid. ${ }^{2}$ Finally, it is worth pointing out that the slope of the viscosity vs shear rate plot in the shearthinning regime is -1 , which means that the shear stress asymptotes to a plateau in this regime. Such a stress plateau is indicative of a shear-banding flow and is another characteristic feature of wormlike micelle rheology. ${ }^{1}$

The effect of $\mathrm{KCl}$ concentration on the zero-shear viscosity $\eta_{0}$ of $50 \mathrm{mM} \mathrm{NaOA}$ solutions is shown in Figure 2. The zeroshear viscosity increases by more than 4 orders of magnitude as the salt concentration is increased. Initially, the surfactant without salt has the viscosity of water $(\sim 1 \mathrm{mPa} \cdot \mathrm{s})$. When ca. $100 \mathrm{mM} \mathrm{KCl}$ is added, there is a sharp increase in $\eta_{0}$ and the viscosity continues to rise until a $\mathrm{KCl}$ concentration of about $400 \mathrm{mM}$. At high $[\mathrm{KCl}]$, the viscosity plateaus around $30 \mathrm{~Pa} \cdot \mathrm{s}$ (i.e., a factor of 30000 increase in viscosity over that of the original surfactant solution). A similar trend, with an initial sharp rise followed by a plateau, is also observed for the relaxation time $t_{\mathrm{R}}$ obtained from dynamic rheology (data not shown).

The above rheological data together reflect the $\mathrm{KCl}$-induced growth of anionic wormlike micelles in $\mathrm{NaOA}$ solutions. The 


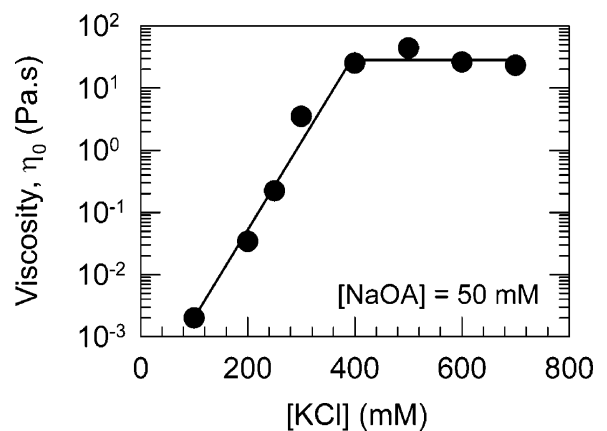

Figure 2. Effect of $\mathrm{KCl}$ concentration on the zero shear viscosity $\eta_{0}$ of $\mathrm{NaOA} / \mathrm{KCl}$ solutions. The $\mathrm{NaOA}$ concentration is $50 \mathrm{mM}$ and the data correspond to $25^{\circ} \mathrm{C}$. The lines are shown to guide the eye.
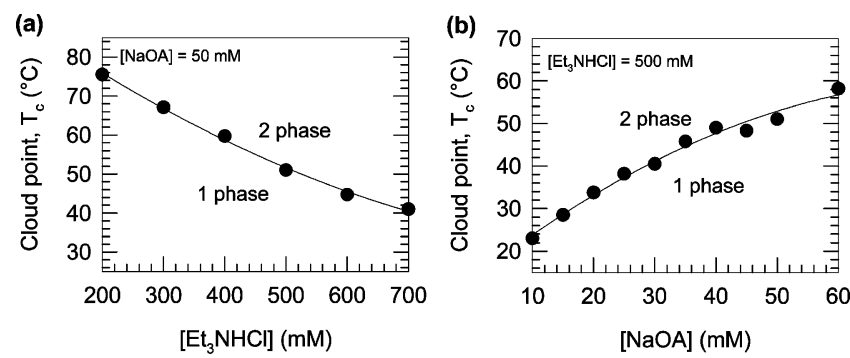

Figure 3. Variation of the cloud point temperature $T_{\mathrm{c}}$ of $\mathrm{NaOA} / \mathrm{Et}_{3}$ $\mathrm{NHCl}$ solutions (a) as a function of $\left[\mathrm{Et}_{3} \mathrm{NHCl}\right]$ for $[\mathrm{NaOA}]=50 \mathrm{mM}$ and (b) as a function of $[\mathrm{NaOA}]$ for $\left[\mathrm{Et}_{3} \mathrm{NHCl}\right]=500 \mathrm{mM}$. Lines through the data, obtained by linear regression, are shown to guide the eye.

addition of salt (increase in ionic strength) facilitates micellar growth by screening the electrostatic repulsions between the negatively charged surfactant headgroups. ${ }^{2}$ As a result, long, flexible anionic wormlike micelles are formed in solution, which, in turn, become entangled into a transient network and thereby impart a high viscosity to the sample. The longer the micelles, the higher the relaxation time and zero-shear viscosity of the solution. ${ }^{1,2}$ The fact that the viscosity plateaus at high salt suggests that the micelles grow up to a point and no further. That is, at high salt, the headgroup reaches a minimum area, and further salt addition has no influence on the electrostatics of headgroup interactions. All these results are very consistent with previously reported trends for cationic wormlike micelles, 2,3 and we can therefore conclude that anionic wormlike micelles are similar to their cationic counterparts.

NaOA/Et ${ }_{3}$ NHCl Solutions. We now describe the effects of adding the triethylammonium salt, $\mathrm{Et}_{3} \mathrm{NHCl}$, to $50 \mathrm{mM} \mathrm{NaOA}$ solutions. Visual inspection of these samples suggested that they were rather viscous fluids at room temperature, although not as viscous as those made with $\mathrm{KCl}$. More interestingly, when the samples were heated, they turned cloudy and eventually separated into two liquid phases. This indicated a cloud point phenomenon or lower consolute phase behavior in $\mathrm{NaOA} / \mathrm{Et}_{3}$ $\mathrm{NHCl}$ solutions. None of the $\mathrm{NaOA} / \mathrm{KCl}$ samples showed a cloud point, however.

The systematic variation of the cloud point temperature $T_{\mathrm{c}}$ as a function of $\left[\mathrm{Et}_{3} \mathrm{NHCl}\right]$ and $[\mathrm{NaOA}]$ is shown in Figure 3. For a fixed $[\mathrm{NaOA}]$ of $50 \mathrm{mM}, T_{\mathrm{c}}$ decreases monotonically with increasing $\left[\mathrm{Et}_{3} \mathrm{NHCl}\right]$ (Figure $3 \mathrm{a}$ ). That is, as the salt concentration increases, the solution turns cloudy at a lower temperature. On the other hand, for a constant $\left[\mathrm{Et}_{3} \mathrm{NHCl}\right]$ of $500 \mathrm{mM}, T_{\mathrm{c}}$ increases with increasing $[\mathrm{NaOA}]$. This means that at a higher surfactant concentration a higher $\left[\mathrm{Et}_{3} \mathrm{NHCl}\right]$ is required to induce clouding. Based on both sets of data, the molar ratio of $\left[\mathrm{Et}_{3}-\right.$ $\mathrm{NHCl}]$ to $[\mathrm{NaOA}]$ seems to control the clouding phenomenon,

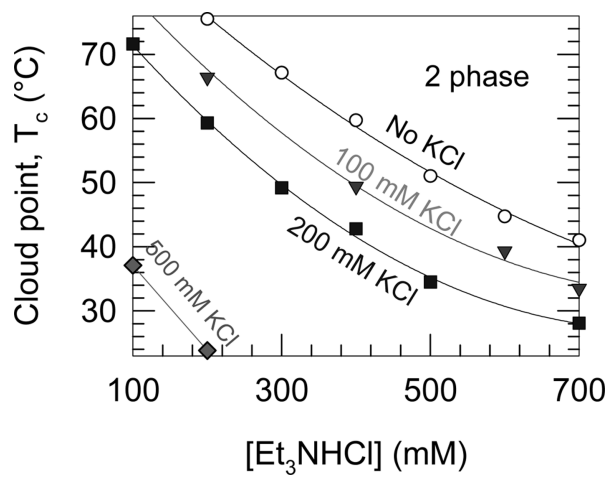

Figure 4. Effect of added $\mathrm{KCl}$ on the cloud points of $\mathrm{NaOA} / \mathrm{Et}_{3} \mathrm{NHCl}$ solutions. The cloud point temperature $T_{\mathrm{c}}$ is plotted as a function of $\left[\mathrm{Et}_{3} \mathrm{NHCl}\right]$ for $[\mathrm{NaOA}]=50 \mathrm{mM}$. The data for no $\mathrm{KCl}(\mathrm{O})$ are reproduced from Figure 3a. Succeeding curves are shown for solutions containing $100(\nabla), 200(\boldsymbol{\square})$, and $500 \mathrm{mM}(\diamond) \mathrm{KCl}$.

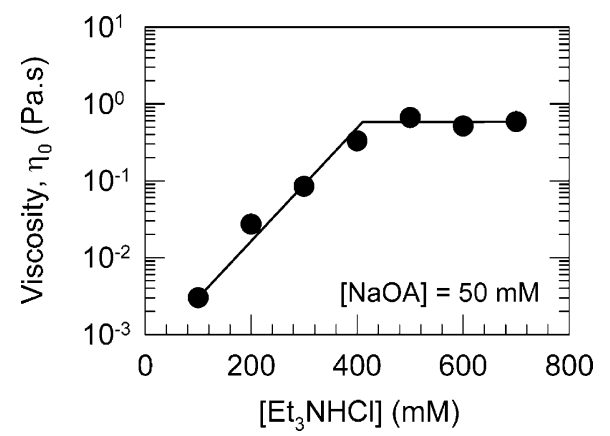

Figure 5. Effect of $\mathrm{Et}_{3} \mathrm{NHCl}$ concentration on the zero shear viscosity $\eta_{0}$ of $\mathrm{NaOA} / \mathrm{Et}_{3} \mathrm{NHCl}$ solutions. The $\mathrm{NaOA}$ concentration is $50 \mathrm{mM}$ and the data correspond to $25^{\circ} \mathrm{C}$.

with the cloud point shifting to lower temperatures as this ratio is increased. This suggests that there is a binding between the triethylammonium counterions and the anionic surfactant. ${ }^{9}$

The clouding of $\mathrm{NaOA}$ solutions in the presence of $\mathrm{Et}_{3} \mathrm{NHCl}$ is unusual for anionic surfactant solutions. As mentioned above, we found no clouding in $\mathrm{NaOA} / \mathrm{KCl}$ solutions, suggesting that the clouding was peculiar to the $\mathrm{Et}_{3} \mathrm{NHCl}$ salt. However, when we added $\mathrm{KCl}$ to $\mathrm{NaOA} / \mathrm{Et}_{3} \mathrm{NHCl}$ solutions, the cloud point behavior was systematically altered, as shown in Figure 4. Here, we plot the cloud point temperature as a function of $\left[\mathrm{Et}_{3} \mathrm{NHCl}\right]$ for a fixed $[\mathrm{NaOA}]$ of $50 \mathrm{mM}$. The data for $T_{\mathrm{c}}$ in the absence of $\mathrm{KCl}$ is reproduced from Figure $3 \mathrm{a}$ and plotted as unfilled symbols. In the presence of $100 \mathrm{mM} \mathrm{KCl}$, the cloud point curve moves down a few degrees over the entire range of [ $\left.\mathrm{Et}_{3} \mathrm{NHCl}\right]$. In other words, clouding is induced at a lower temperature or, equivalently, the two-phase region is broadened. Increasing the $\mathrm{KCl}$ concentration to $200 \mathrm{mM}$ further broadens the two-phase region, and finally, for $500 \mathrm{mM} \mathrm{KCl}$, the onset of clouding is moved down to room temperature for most samples. Thus, the addition of $\mathrm{KCl}$ increases the propensity to cloud; i.e., the system destabilizes at a lower temperature.

Having described the phase behavior of $\mathrm{NaOA} / \mathrm{Et}_{3} \mathrm{NHCl}$ solutions, we now consider the rheology of these solutions as a function of $\left[\mathrm{Et}_{3} \mathrm{NHCl}\right]$ and temperature. The zero-shear viscosity $\eta_{0}$ of $50 \mathrm{mM} \mathrm{NaOA}$ solutions as a function of $\left[\mathrm{Et}_{3} \mathrm{NHCl}\right]$ is shown in Figure 5. $\eta_{0}$ increases by about 3 orders of magnitude and reaches a plateau at high $\mathrm{Et}_{3} \mathrm{NHCl}$ concentrations (around ca. $400 \mathrm{mM}$ ). The plateau value of $\eta_{0}$ in this case is around 0.8 $\mathrm{Pa} \cdot \mathrm{s}$, i.e., around 800 times the viscosity of water. This is significantly lower than the plateau viscosity obtained with $\mathrm{KCl}$. Note that both the $\mathrm{KCl}$ and $\mathrm{Et}_{3} \mathrm{NHCl}$ solutions exhibit a very similar rheology (compare the steady-shear responses in Figures 

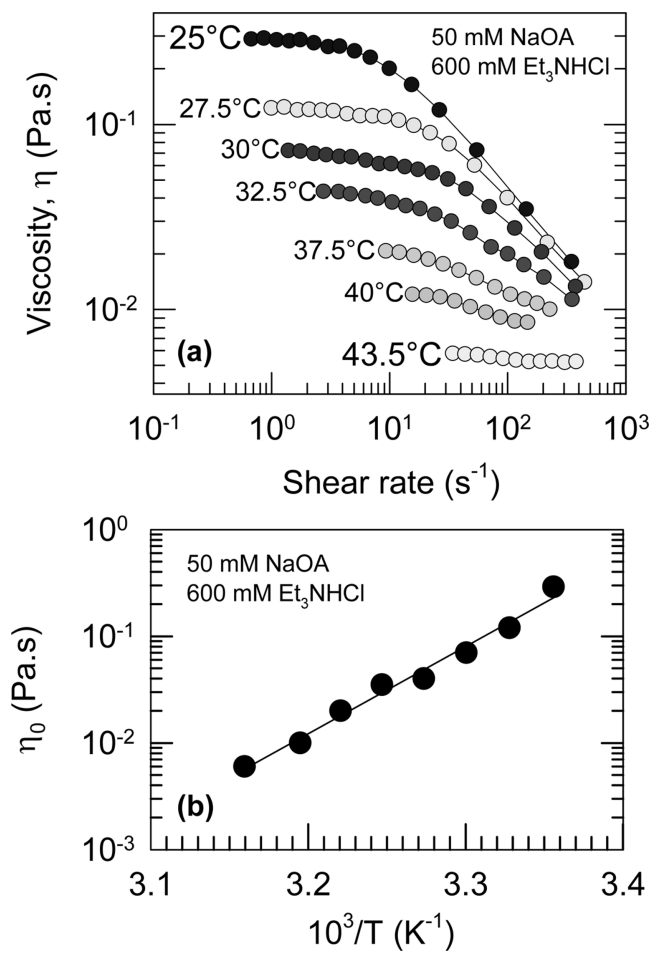

Figure 6. Effect of temperature on the steady-shear rheology of $\mathrm{NaOA} /$ $\mathrm{Et}_{3} \mathrm{NHCl}$ solution. The sample contains $50 \mathrm{mM} \mathrm{NaOA}$ and $600 \mathrm{mM}$ $\mathrm{Et}_{3} \mathrm{NHCl}$ and has a cloud point at $44.5^{\circ} \mathrm{C}$. (a) Viscosity vs shear rate data for a series of temperatures. (b) Zero-shear viscosity $\eta_{0}$ vs $1 / T$ in a semilog (Arrhenius) plot, where $T$ is the absolute temperature.

$1 \mathrm{~b}$ and 6a), except that the latter are less viscous. We can conclude that $\mathrm{Et}_{3} \mathrm{NHCl}$ also induces the growth of anionic wormlike micelles, although the micelles do not become quite as long.

Figure 6 shows the effect of temperature on the steady-shear rheology of a $50 \mathrm{mM} \mathrm{NaOA}+600 \mathrm{mM} \mathrm{Et}_{3} \mathrm{NHCl}$ sample. The sample clouds at $44.5^{\circ} \mathrm{C}$, and viscosity plots are shown in Figure 6 a for temperatures from the ambient to the vicinity of the cloud point. The data reveal that the sample becomes less viscous upon heating. The sample shear-thins at low temperatures, while it behaves like a Newtonian fluid at high temperatures. The zeroshear viscosity $\eta_{0}$ decreases exponentially up to the cloud point, as shown by the Arrhenius plot of $\log \eta_{0}$ vs $1 / T$ in Figure $6 \mathrm{~b}$. An exponential decay is in accordance with the well-known relation for wormlike micelles: ${ }^{1,3}$

$$
\eta_{0}=A \mathrm{e}^{E_{\mathrm{a}} / R T}
$$

where $E_{\mathrm{a}}$ is the flow activation energy, $R$ is the gas constant, and $A$ is a preexponential factor. From the slope of the straight line fit in Figure 6b, we calculate the flow activation energy $E_{\mathrm{a}}$ to be about $157 \mathrm{~kJ} / \mathrm{mol}$. This value of $E_{\mathrm{a}}$ is comparable to those reported for other wormlike micelles. ${ }^{3}$ Thus, the rheology of this sample is no different from that of a typical wormlike micellar fluid even though this sample displays a cloud point. Note that the exponential decay in viscosity with temperature implies an exponential reduction in wormlike micellar length as the temperature is raised. ${ }^{3}$

Similar rheological results as a function of temperature were obtained with all the $\mathrm{NaOA} / \mathrm{Et}_{3} \mathrm{NHCl}$ samples studied. These rheological studies indicate that the micelles become shorter upon heating, right up to the cloud point. (An increase in micelle size with temperature would have caused an increase, not a decrease in viscosity.) Thus, clouding is not preceded by micellar

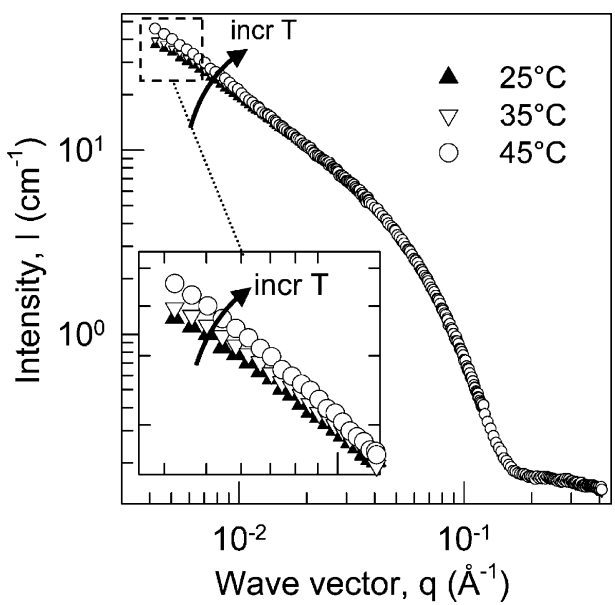

Figure 7. Effect of temperature on the SANS scattering from an $\mathrm{NaOA} /$ $\mathrm{Et}_{3} \mathrm{NHCl}$ solution. The sample contains $50 \mathrm{mM} \mathrm{NaOA}$ and $500 \mathrm{mM}$ $\mathrm{Et}_{3} \mathrm{NHCl}$ and clouds at $51^{\circ} \mathrm{C}$. The inset is a magnification of the low- $q$ data.

growth into larger aggregates and the micelle size does not diverge at the cloud point. Instead, the clouding seems to be induced by attractive interactions between the micelles at high temperatures, evidence for which also comes from SANS, as discussed below.

Figure 7 shows the SANS intensity $I$ as a function of the wave vector $q$ for a $50 \mathrm{mM} \mathrm{NaOA}+500 \mathrm{mM} \mathrm{Et}_{3} \mathrm{NHCl}$ sample in $\mathrm{D}_{2} \mathrm{O}$. The phase behavior of the system in $\mathrm{D}_{2} \mathrm{O}$ is very similar to that in $\mathrm{H}_{2} \mathrm{O}$, with the cloud points coinciding within $0.5^{\circ} \mathrm{C}$. The above sample had a cloud point around $51^{\circ} \mathrm{C}$, and SANS spectra are shown at 25,35 , and $45{ }^{\circ} \mathrm{C}$. We find that the intensities are practically identical at high $q$ whereas there is an upturn in the low- $q$ intensity with increasing temperature. The upturn cannot be attributed to micellar growth because it would be inconsistent with the rheological data. Instead, the low- $q$ upturn with increasing temperature must be due to the onset of attractive interactions between the micelles. A similar upturn in SANS intensity has been observed near the cloud point for other micellar systems as well, and there also the upturn has been associated with attractive intermicellar interactions. ${ }^{9,19}$

It is worth pointing out a couple of other features in the SANS data. First, the absence of an interaction peak means that electrostatic repulsions between the anionic headgroups are screened by the salt. Second, the fact that the SANS data coincide at high $q$ implies that the micellar radius remains unchanged with increasing temperature. Note that the dominant contribution to the high- $q$ scattering is from the micellar form factor $P(q)$, since the structure factor $S(q) \rightarrow 1$ in this $q$ range. We can extract the radius of the wormlike micelles by plotting the high- $q$ data in the form $\ln (I q)$ vs $q^{2}$ (a Guinier-like plot). ${ }^{20}$ This plot is a straight line (data not shown), and from the slope the micellar radius is calculated to be $21.5 \AA$. This is a reasonable value of the radius for $\mathrm{NaOA}$ micelles, since it is close to the length of a fully extended, monounsaturated $\mathrm{C}_{18}$ chain (ca. $25 \AA$ ). To obtain further information on our micelles such as their contour length or the strength of attractive interactions, we have to model the structure factor for interacting flexible cylinders. This is beyond the scope of this paper and is not attempted here.

NaOA Solutions with Other Salts. So far we have contrasted the results obtained for two salts, $\mathrm{KCl}$ and $\mathrm{Et}_{3} \mathrm{NHCl}$, when added to $\mathrm{NaOA}$ solutions. To recap, we found that adding $\mathrm{KCl}$ made the solutions highly viscous, but the solutions did not cloud. Adding $\mathrm{Et}_{3} \mathrm{NHCl}$, on the other hand, gave rise to viscous 


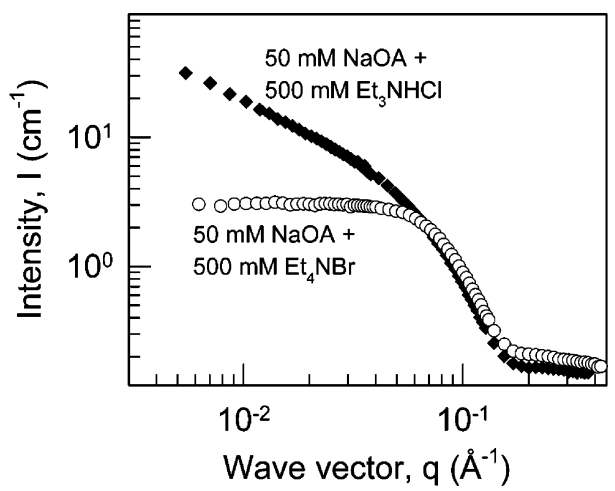

Figure 8. SANS scattering at $25^{\circ} \mathrm{C}$ from $\mathrm{NaOA}$ solutions containing quarternary and tertiary ammonium salts. The $\mathrm{NaOA}$ concentration in both solutions is $50 \mathrm{mM}$. One solution contains $500 \mathrm{mM} \mathrm{Et}_{3} \mathrm{NHCl}$ (tertiary ammonium salt), while the other has the same concentration of $\mathrm{Et}_{4} \mathrm{NBr}$ (quarternary ammonium salt).

solutions that also clouded upon heating. We now report our preliminary findings with two quarternary ammonium salts, Et 4 $\mathrm{NBr}$ and $\mathrm{Bu}_{4} \mathrm{NBr}$. As pointed out earlier, the $\mathrm{Bu}_{4} \mathrm{NBr}$ salt is known to cause clouding in solutions of anionic surfactants such as SDS. Surprisingly, however, we did not observe clouding of $\mathrm{NaOA}$ solutions with either of these salts, nor did we detect a significant increase in viscosity. Thus, the quarternary ammonium salts have a very different effect on $\mathrm{NaOA}$ solutions compared to the tertiary ammonium salt, $\mathrm{Et}_{3} \mathrm{NHCl}$.

The contrast between the quarternary and tertiary ammonium salts $\mathrm{Et}_{4} \mathrm{NBr}$ and $\mathrm{Et}_{3} \mathrm{NHCl}$ was also probed by SANS. Figure 8 shows the scattering at $25{ }^{\circ} \mathrm{C}$ from two NaOA solutions, one with $500 \mathrm{mM} \mathrm{Et}_{3} \mathrm{NHCl}$ and the other with $500 \mathrm{mM} \mathrm{Et}_{4} \mathrm{NBr}$. The two scattering patterns are very different, with the $\mathrm{Et}_{3} \mathrm{NHCl}$ sample showing a much higher scattered intensity at low $q$. While the $\mathrm{Et}_{3} \mathrm{NHCl}$ scattering is characteristic of long cylindrical micelles, the $\mathrm{Et}_{4} \mathrm{NBr}$ scattering reflects the presence of small, globular micelles. Note that the $\mathrm{Et}_{4} \mathrm{NBr}$ data do not show an interaction peak, which suggests that the electrostatic charge on the anionic micelles is fully screened. The radius of the spherical $\mathrm{Et}_{4} \mathrm{NBr}$ micelles can be obtained by constructing a Guinier plot of the data (not shown), and the radius obtained from this plot is about $27.5 \AA$. The SANS scattering for the $\mathrm{Et}_{4} \mathrm{NBr}$ sample was invariant with temperature, suggesting that there was a negligible change in micelle size or in intermicellar interactions upon heating.

\section{Discussion}

This study has opened up a series of questions on the phase behavior and rheology of anionic surfactant micelles. The key questions are as follows: (i) Why do some salts induce anionic surfactants to form wormlike micelles (and thus give rise to viscoelastic fluids)? (ii) Why do certain salts induce anionic micellar solutions to cloud upon heating? (iii) Are the phase behavior and rheology of anionic micellar fluids connected?

Formation of Anionic Wormlike Micelles. Let us consider the formation of wormlike micelles first. It is useful to view this in terms of the surfactant packing parameter $p=v / l a$, where $v$ is the surfactant tail volume, $l$ is the tail length, and $a$ is the effective area of the surfactant headgroups. ${ }^{8}$ A value of $p$ around $1 / 3$ implies the formation of spherical micelles. An increase in ionic strength screens the repulsions between ionic headgroups, thus reducing the effective headgroup area $a$. The packing parameter $p$ thereby increases from $1 / 3$ to about $1 / 2$, and the micelles consequently grow from spheres to cylinders or worms. This explains why the addition of $\mathrm{KCl}$ to $\mathrm{NaOA}$ solutions

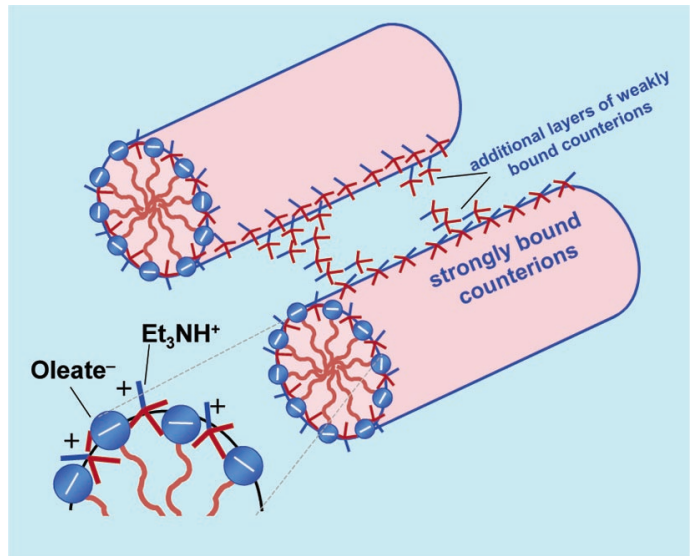

Figure 9. Schematic showing interaction between $\mathrm{NaOA}$ and $\mathrm{Et}_{3} \mathrm{NH}^{+}$ counterions in a rodlike micelle as well as attractive interactions between adjacent micelles upon heating. $\mathrm{The}^{\mathrm{E}} \mathrm{NH}_{3} \mathrm{NH}^{+}$counterions are shown to be strongly bound to the micelle with two ethyl tails embedded in the hydrophobic core and one tail dangling into the water. Additional layers of weakly bound $\mathrm{Et}_{3} \mathrm{NH}^{+}$counterions are also shown. The attractive interaction is visualized as being mediated by the layer(s) of bound counterions, with the dangling ethyl tails thought to play a prominent role.

induces the growth of wormlike micelles and thereby leads to a viscoelastic sample. ${ }^{2}$

On the other hand, no micellar growth is observed upon addition of $\mathrm{Et}_{4} \mathrm{NBr}$ or $\mathrm{Bu}_{4} \mathrm{NBr}$ to $\mathrm{NaOA}$, even though the ionic strength is equally high. The SANS data for $\mathrm{Et}_{4} \mathrm{NBr}$ (Figure 8) show that the repulsions between $\mathrm{NaOA}$ headgroups are screened by the salt, yet the micelles did not grow. A plausible explanation is that the $\mathrm{Et}_{4} \mathrm{~N}^{+}$counterions do bind to $\mathrm{NaOA}$ micelles, but the geometry of the resulting surfactant-counterion complex does not favor the formation of cylindrical micelles. The binding of tetraalkylammonium counterions to anionic micelles is well documented. ${ }^{10,15} \mathrm{Et}_{4} \mathrm{~N}^{+}$can bind by inserting its ethyl tails into the hydrophobic interior of a micelle; however, not all four tails can be inserted due to geometric limitations. ${ }^{10}$ Because one or two tails remain exposed to water, the binding of $\mathrm{Et}_{4} \mathrm{~N}^{+}$to $\mathrm{NaOA}$ will be relatively weak and the $\mathrm{Et}_{4} \mathrm{~N}^{+}$ counterion will protrude into the headgroup area. Thus, while the counterions mitigate the headgroup charge, they also occupy extra space at the headgroup. As a result, the headgroup area remains high and the packing parameter $p$ remains around $1 / 3$ despite the binding of salt. This can explain why the micelles formed in the presence of $\mathrm{Et}_{4} \mathrm{NBr}$ remain spherical.

In comparison to $\mathrm{Et}_{4} \mathrm{NBr}$, the tertiary ammonium salt $\mathrm{Et}_{3}$ $\mathrm{NHCl}$ is expected to bind more strongly to anionic micelles. This is because the three-tailed $\mathrm{Et}_{3} \mathrm{NH}^{+}$counterion can penetrate deeper into the micelle interior, leaving at most one ethyl tail exposed to the water (Figure 9). In turn, based on the geometry of $\mathrm{Et}_{3} \mathrm{NH}^{+}$at the micellar interface, there is a net reduction in headgroup area due to the lowering of micellar surface charge. Thus, the packing parameter $p$ increases, thereby inducing a sphere-to-cylinder transition in the micelles. Presumably, though, the surfactant geometry in the presence of bound $\mathrm{Et}_{3} \mathrm{NH}^{+}$ counterions is still not as favorable for micellar growth as in the presence of nonbinding $\mathrm{KCl}$ at high ionic strength. This would explain why the viscosity in the presence of $\mathrm{Et}_{3} \mathrm{NHCl}$ is much lower than that in the presence of $\mathrm{KCl}$.

Clouding of Anionic Wormlike Micelles. As discussed in the Introduction, cloud point phenomena, i.e., phase separation upon heating, is quite rare for ionic micellar fluids. In light of existing reports, ${ }^{9-16}$ there appear to be two key requirements for clouding to occur in solutions containing an ionic surfactant 
and a salt. First, the counterion from the salt must strongly bind to the ionic micelles - this is a necessary, but not sufficient, condition. Second, there must be a mechanism to induce attractive interactions between the micelles with increasing temperature.

The above reasoning can account for our data. We had suggested above that $\mathrm{Et}_{3} \mathrm{NH}^{+}$counterions bind strongly to $\mathrm{NaOA}$ micelles whereas $\mathrm{Et}_{4} \mathrm{~N}^{+}$and $\mathrm{Bu}_{4} \mathrm{~N}^{+}$counterions bind weakly. Weakly bound counterions may easily dissociate from the micellar surface upon heating, which might explain why there are no attractive interactions between micelles with bound $\mathrm{Et}_{4} \mathrm{~N}^{+}$or $\mathrm{Bu}_{4} \mathrm{~N}^{+}$at high temperatures. On the other hand, in the case of $\mathrm{NaOA} / \mathrm{Et}_{3} \mathrm{NH}^{+}$micelles, attractive interactions might indeed occur at high temperatures due to the strongly bound counterions. At low temperatures, the micelles will repel because the headgroups are covered by a shell of structured water. At higher temperatures, the removal of the structured water shell could permit the bound $\mathrm{Et}_{3} \mathrm{NH}^{+}$counterions on adjacent $\mathrm{NaOA}$ micelles to interact. As suggested previously, ${ }^{10}$ the orientation of $\mathrm{Et}_{3} \mathrm{NH}^{+}$counterions at the micelle interface may be responsible for the attractive interactions. $\mathrm{Et}_{3} \mathrm{NH}^{+}$ions are expected to orient with one of their three ethyl tails exposed to water (Figure 9), and the dangling ethyl tails on adjacent micelles would tend to adhere together, owing to the hydrophobic effect. This could induce an attractive interaction between the $\mathrm{NaOA}$ micelles, which ultimately leads to clouding.

Our interpretation above is similar to that originally proposed by $\mathrm{Yu}$ and $\mathrm{Xu} .{ }^{10}$ Bales and Zana ${ }^{14,15}$ recently pointed out that additional layers of loosely adsorbed counterions could also be present near the micelle surface, as depicted in Figure 9. These additional layers could serve as a bridge between the dangling ethyl tails on adjacent micelles and thereby mediate the attractive interactions. This idea could be useful in understanding why the cloud point temperature decreases with increasing $\mathrm{Et}_{3} \mathrm{NHCl} /$ $\mathrm{NaOA}$ molar ratio (Figure 3). A higher value of this ratio could mean (a) a higher density of ethyl tails dangling from each micelle, and/or (b) a thicker layer of weakly adsorbed counterions surrounding each micelle. In either case, we would expect an increase in attractive interactions as the $\mathrm{Et}_{3} \mathrm{NHCl} / \mathrm{NaOA}$ ratio increases, which in turn would mean an earlier onset of clouding. This is indeed what is observed.

We also found that the addition of the inorganic, nonbinding salt $\mathrm{KCl}$ to an $\mathrm{NaOA} / \mathrm{Et}_{3} \mathrm{NHCl}$ sample lowers the cloud point temperature (Figure 4). At first glance this seems like a saltinduced screening of electrostatic repulsions between anionic micelles, but this explanation is unlikely. In the first place, the binding of $\mathrm{Et}_{3} \mathrm{NHCl}$ is probably enough to minimize the surface charge on NaOA micelles, as suggested by the SANS data (Figure 8). Second, the entire cloud point curve is lowered by adding $\mathrm{KCl}$, with the lowering being proportional to the $\mathrm{KCl}$ concentration. This strongly suggests that $\mathrm{KCl}$ is exerting a "salting-out" effect on the cloud point behavior, much like its effect on the cloud point curves of nonionic surfactants. ${ }^{8}$ The "salting-out" effect arises when small, polarizable salt ions become highly hydrated and thereby increase the structure of water. The hydration of salt ions comes at the expense of the surfactant headgroups, which get dehydrated more easily. Consequently, the system "salts-out", i.e., phase separates, at a lower temperature.

Finally, we examine whether the rheology and cloud point behavior of $\mathrm{NaOA} / \mathrm{Et}_{3} \mathrm{NHCl}$ solutions are connected. We believe that a connection does exist, because both phenomena are driven by the binding of counterions to anionic micelles. The strong binding of $\mathrm{Et}_{3} \mathrm{NH}^{+}$counterions increases the surfactant packing parameter and promotes the growth of wormlike $\mathrm{NaOA}$ micelles. We believe it is the same counterion binding that induces attractive interactions between the $\mathrm{NaOA}$ micelles at high temperatures. In other words, a high fraction of bound $\mathrm{Et}_{3} \mathrm{NH}^{+}$ counterions gives rise to long micelles at low temperatures and the same samples cloud when warmed by a few degrees. At high salt concentrations, the solution viscosity increases to a plateau while the cloud point temperature decreases toward an eventual plateau.

\section{Conclusions}

Our studies on the $\mathrm{C}_{18}$-tailed anionic surfactant $\mathrm{NaOA}$ have revealed interesting rheology as well as phase behavior. First, we have shown that $\mathrm{NaOA}$ can self-assemble into wormlike micelles upon addition of either a simple, inorganic salt (e.g., $\mathrm{KCl})$ that screens the intermicellar electrostatic interactions, or a binding salt (e.g., $\mathrm{Et}_{3} \mathrm{NHCl}$ ) that reduces the micellar surface charge. Second, we have demonstrated cloud point behavior in solutions of $\mathrm{NaOA}$ and $\mathrm{Et}_{3} \mathrm{NHCl}$. We attribute the clouding to the onset of attractive interactions between the anionic micelles at high temperatures. These interactions arise on account of the geometry of strongly bound $\mathrm{Et}_{3} \mathrm{NH}^{+}$counterions at the micelle surface. Strong binding of counterions is postulated to be a necessary condition for cloud point phenomena; the lack of cloud points in the case of quarternary amine salts is attributed to weaker binding of their counterions.

Acknowledgment. We would like to acknowledge NIST for facilitating the SANS experiments performed as part of this work.

\section{References and Notes} 6869

(1) Cates, M. E.; Candau, S. J. J. Phys.: Condens. Matter 1990, 2,

(2) Hoffmann, H. In Structure and Flow in Surfactant Solutions; Herb, C. A., Prud'homme, R. K., Eds.; American Chemical Society: Washington, DC, 1994

(3) Raghavan, S. R.; Kaler, E. W. Langmuir 2001, 17, 300.

(4) Yang, J. Curr. Opin. Colloid Interface Sci. 2002, 7, 276.

(5) Magid, L. J.; Li, Z.; Butler, P. D. Langmuir 2000, 16, 10028. 2543.

(6) Hassan, P. A.; Raghavan, S. R.; Kaler, E. W. Langmuir 2002, 18

(7) Maitland, G. C. Curr. Opin. Colloid Interface Sci. 2000, 5, 301.

(8) Jonsson, B.; Lindman, B.; Holmberg, K.; Kronberg, B. Surfactants and Polymers in Aqueous Solutions; Wiley: New York, 1998. 1056.

(9) Raghavan, S. R.; Edlund, H.; Kaler, E. W. Langmuir 2002, 18 ,

(10) Yu, Z. J.; Xu, G. Z. J. Phys. Chem. 1989, 93, 7441.

(11) Kumar, S.; Sharma, D.; Kabir ud, D. Langmuir 2000, 16, 6821.

(12) Kumar, S.; Sharma, D.; Khan, Z. A.; Kabir ud, D. Langmuir 2001 17, 5813 .

(13) Kumar, S.; Aswal, V. K.; Naqvi, A. Z.; Goyal, P. S.; Kabir ud, D. Langmuir 2001, 17, 2549.

(14) Bales, B. L.; Zana, R. Langmuir 2004, 20, 1579.

(15) Bales, B. L.; Tiguida, K.; Zana, R. J. Phys. Chem. B 2004, 108 , 14948

(16) Mata, J.; Varade, D.; Ghosh, G.; Bahadur, P. Colloids Surf. A 2004, 245,69 .

(17) Casero, I.; Sicilia, D.; Rubio, S.; Perez-Bendito, D. Anal. Chem. 1999, 71,4519 .

(18) de Mul, M. N. G.; Davis, H. T.; Evans, D. F.; Bhave, A. V.; Wagner, J. R. Langmuir 2000, 16, 8276 .

(19) Hayter, J. B.; Zulauf, M. Colloid Polym. Sci. 1982, 260, 1023.

(20) Koehler, R. D.; Raghavan, S. R.; Kaler, E. W. J. Phys. Chem. B 2000, 104, 11035 